\title{
Consent and parental responsibility - the past, the present and the future
}

\author{
Asma Keshtgar, ${ }^{\star 1}$ Mohamed Hania ${ }^{1}$ and Mohammad 0. Sharif²
}

\section{Key points}

This paper explores the guidance on consent and parental responsibility within the UK.
The main aspects of parental responsibility are succinctly summarised with a helpful flowchart.
Considerations of telephone and video consultations for clinicians and patients, and their implications for consent, are discussed.

\begin{abstract}
Introduction Informed consent is the 'permission or agreement' given by the patient for a proposed action. This paper explores the clinician's role in obtaining informed consent, provides an overview of consent and parental responsibility in the UK, and presents practical adjuncts to aid dental professionals in ascertaining who has parental responsibility to delineate persons capable of providing assent on behalf of an underage patient.
\end{abstract}

Consent and parental responsibility While the principles of consent have largely stayed constant with time, subtleties in parental responsibility legislation exist in different regions of the UK. An audit exploring consent and parental responsibility knowledge among clinicians within the orthodontic department at the UCLH Eastman Dental Hospital demonstrated that none of the respondents met the gold standard (100\%). The results ranged from 59-89\% with a mean score of $74 \%$. The majority of questions answered incorrectly related to knowledge of parental responsibility.

Conclusion It is the responsibility of clinicians providing any care within the UK to stay up to date with legislation and regulations regarding consent and parental responsibility. Knowledge-based questionnaires can highlight areas of knowledge deficit which can be addressed through continuous professional development. This paper provides a flowchart summarising parental responsibility and a prefilled parental responsibility questionnaire as adjuncts to simplify the process of dental professionals ascertaining parental responsibility.

\section{Introduction}

A fundamental and foundational aspect for the provision of elective treatment is the consent process; the 'permission or agreement' granted by the patient for a proposed action (in this case, treatment) to occur. Following the decision in Montgomery v Lanarkshire Health Board in 2015, the law in respect of consent in healthcare has changed considerably. Rightly, there is a greater emphasis on a patient's autonomy along with an impetus to discuss all material risks while incorporating shared decision making as a key tenet of our day-today practice. Healthcare by its very nature is a

'Specialist Registrar in Orthodontics, Eastman Dental Hospital, University College London Hospitals NHS Foundation Trust,

London, UK; ${ }^{2}$ Specialist in Orthodontics, London, UK.

*Correspondence to: Asma Keshtgar

Email address: asma.keshtgar@nhs.net

Refereed Paper.

Accepted 24 February 2021

https://doi.org/10.1038/s41415-022-3877-7 progressive discipline; we strive to constantly review/change our modus operandi with the aim of improving patient outcomes. Consent as a fundamental tenet of healthcare is not exempt from this state of flux. It is our aim in this paper to discuss the past, present and future approaches to informed consent in healthcare. The use of teleclinics will also be discussed as part of both current and future practices.

\section{Consent and parental responsibility}

Consent

Informed consent is a continuous process, defined as 'the voluntary and informed decision of a person with capacity to undergo a particular treatment.' ${ }^{1}$ Clear guidelines on obtaining informed consent have been established by the General Dental Council (GDC), therefore placing it as an ethical and legal obligation for all UK dental professionals. Valid consent must be obtained before commencing any elective treatment and discussions with the patient should be recorded as evidence of the consent process. Discussions should include treatment options (including the option to receive no treatment at all), costs, risks, likely benefits, expected prognosis and the probable outcome if the suggested treatment is not undertaken. ${ }^{2}$

Undertaking a procedure without consent is a breach of the duty for the clinician and may leave the clinician open to allegations of negligence or, in extreme cases, criminal charges of assault and/or bodily harm. ${ }^{3}$ Previously, the 'Bolam principle' was the conventional test for ascertaining the level of information necessary to avoid liability in cases of negligence. In essence, it determines whether a responsible body of clinicians skilled in that particular sphere would support the approach taken. ${ }^{4}$ There has since been a paradigm shift in focus from the 'reasonable clinician' to the 'reasonable patient'. Since the Montgomery ruling, it is now a requirement for clinicians to discuss all 'material risks' with the patient. 
This entails the clinician discussing risks which are significant for the patient or a risk which a reasonable individual in the same position as the patient would likely attach significance to, even if those risks would not be 'significant' or 'material' in the eyes of the clinician. ${ }^{5}$ What might be minimal risk to one individual might be intolerable to the next. Similarly, there has been a shift from paternalistic medicine to greater empowerment for patients, with 'shared decision making' now being a statutory requirement. ${ }^{6,7}$ In essence, shared decision making is 'a collaborative process through which a clinician supports a patient to reach a decision about their treatment ${ }^{8}$ and has been evidenced to enhance patient and clinician outcomes. ${ }^{9,10,11}$

\section{Parental responsibility}

The process in obtaining consent for an under 16-year-old patient from a parent or a guardian is further upended by the statue regulations. Parental responsibility confers the legal right of the parents/guardians to consent to treatment on behalf of their children. While in the majority of cases, parental responsibility is afforded to the parents/legal guardians of a child, it is important to note that despite the obvious role played by a particular parent in the care and nurturing of their child, not all biological parents have parental responsibility under UK law.

Although children under the age of 18 years are regarded as minors, a child is deemed as capable of consenting to treatment once they reach the age of 16 in England, Scotland, Wales and Northern Ireland. Interestingly, individuals with parental responsibility cannot override valid and informed consent to treatment obtained from a child aged 16 or over; however, in some instances, the child's parents, legal guardians or the court can override refusal of consent by the child. It is therefore advisable to additionally obtain informed consent from a child aged 16-18 years and ask their permission to discuss treatment with individuals who retain parental responsibility where appropriate, for example in cases of surgery (especially if a general anaesthetic is required). Clear documentation of both the patients' permission and discussion with their guardian should be recorded in the patients' notes. ${ }^{12}$

The capacity of a child under the age of 16 can be assessed using the principle of 'Gillick competence' by ascertaining if the child has adequate understanding to fully comprehend what is involved in a proposed treatment, including the purpose, nature, possible risks and benefits, likelihood of success and alternative options. A child with Gillick competence can consent to some treatments; however, may not be able to consent to other decisions that may require greater understanding. Thus, each specific decision requires an assessment of Gillick competence. ${ }^{13}$ In cases where the child is not Gillick competent, an individual with parental responsibility can provide consent on the child's behalf.

Revision to UK legislation has had the ramification for whether unmarried, biological fathers have parental responsibility for their child. This is both chronologically and geographically dependent: ${ }^{14}$

- If the child was born in England or Wales, an unmarried biological father will only acquire parental responsibility if recorded on the child's birth certificate from 1 December 2003

- If the child was born in Northern Ireland, an unmarried biological father will only acquire parental responsibility if recorded on the child's birth certificate from 15 April 2002

- If the child was born in Scotland, an unmarried biological father will only acquire parental responsibility if recorded on the child's birth certificate from 4 May 2006.

Hence, an unmarried biological father whose child's birth was registered before the dates mentioned, or whose name is not recorded on the birth certificate, will not legally have the parental responsibility privilege to consent for treatment on behalf of their child. This is in contrast to all biological mothers, who automatically acquire parental responsibility at the time of birth, along with biological fathers who are married to the mother at the time of birth or subsequently (even if now separated).

The same regulations above apply to children born abroad. In these cases, regulatory applicability can be facilitated by using their current country of residence.

A biological father who does not possess parental responsibility can gain the right to do so via three legal avenues:

1. Obtaining court-registered parental responsibility with agreement with the mother

2. Obtaining a Parental Responsibility Order from the court

3. Obtaining a Residence Order from the court.
Similar legal avenues can be used by stepparents or civil partners to gain parental responsibility for their non-biological children.

It is important to note that parents cannot relinquish their parental responsibility, even if divorced or separated. Parental responsibility cannot be revoked, even for a parent who has no contact with the child or makes no financial contribution to the child.

For adopted children, the adoptive parents acquire parental responsibility once the process of adoption is complete. Likewise, for children born under a surrogacy arrangement, the parental responsibility will reside with the biological mother until one of the following is completed:

1. The intended parent(s) obtain(s) a Parental Order from the court under the Human Fertilisation and Embryology Act 1990, or 2. The intended parents adopt the child.

For children who are subject to a care or supervision order, the local authority gains parental responsibility in addition to whoever already has parental responsibility. Hence, it is rare for foster parents to have parental responsibility. The clinical flowchart in Figure 1 provides an overview of individuals who may have parental responsibility.

\section{Knowledge of consent and parental responsibility}

On searching the literature, we were unable to find papers published that assess knowledge of dental clinicians in regard to both consent and parental responsibility. Therefore, the authors decided to conduct a knowledge-based audit within the orthodontic department at the UCLH Eastman Dental Hospital. A 19-item questionnaire relating to consent and parental responsibilities was piloted, revised and disseminated to all orthodontic clinicians in the department. The gold standard was for $100 \%$ of questions to be answered correctly as knowledge of consent and parental responsibility is essential. (The knowledgebased questionnaire is available upon request from the authors).

Thirty orthodontic clinicians, including registrar trainees, specialists and consultants, completed the questionnaire, with a mean score of $74 \%$, (range $59-89 \%$ ). None of the respondents met the gold standard. Of note, most questions answered incorrectly related to knowledge of parental responsibility, indicating that the majority of knowledge 
deficit related to the parental-responsibilityscenario-based questions. Provision of revision lectures on consent and parental responsibility to the orthodontic department resulted in an improvement of clinician knowledge in this topic area. Additionally, a flowchart summarising parental responsibility (Fig. 1) and a prefilled parental responsibility questionnaire (Appendix 1) was incorporated to simplify the process for ascertaining parental responsibility within the department.

\section{The future - teleclinics}

The unprecedented COVID-19 pandemic has provided dental clinicians with an opportunity to reconsider our current practice. As clinicians, we have a natural inclination of 'festina lente' or 'make haste slowly' when incorporating changes in healthcare. This approach allows us to methodically introduce positive changes (albeit slowly) to minimise the effect of any unintended/less than ideal outcomes. While ideally, we would have preferred ample notice to introduce changes in our clinical practice, the current COVID19 climate has resulted in substantial changes in healthcare delivery, particularly with regard to the promotion and increased utilisation of essential tele/virtual consultations, designed to increase adherence of the governmentmandated ban on non-essential travel and social distancing guidance.

\section{Preparing for a virtual consultation}

Firstly, clinicians must determine whether conducting a virtual consultation is appropriate. It is desirable for virtual consultations to be undertaken for patients already known to the clinical team where possible, as dental records would be available and the dentist and patient are able to reliably identify one another. ${ }^{15}$ The GMC has published a flowchart to aid the clinician in deciding whether a virtual or faceto-face consultation is most appropriate ${ }^{16}$ and NHS England has produced a guide for doctors in conducting video consultations. ${ }^{17}$

Various NHS-approved platforms for video clinics exist which comply with relevant data protection regulations, such as AccuRx, Egton
Medical Information Systems, The Phoenix Partnership and Vision. In urgent situations, clinicians can use commercial, non-NHS approved products such as Zoom or Skype to conduct video consultations if the clinician judges the benefits of the patient consultation to outweigh the risks of using a non-secure platform. Patients must be well-advised of the security and quality of the virtual consultation when scheduling the appointment time, to allow informed consent.

\section{During the virtual consultation}

As part of respecting patients' confidentiality, clinicians must ensure adequate privacy during the teleclinic by using an appropriate room and privacy notices. It is essential for effective protocols to be followed. A key aspect is for the clinician to clearly introduce themselves by name, role and position so that the patient and/or parent/carer are certain who they are talking to. Next, the patient's identity and that of any individual spoken with should be confirmed, to ensure the correct patient has been contacted and to ascertain whether the

Fig. 1 Flowchart summarising individuals with parental responsibility

Clinical flowchart - consent and parental responsibility

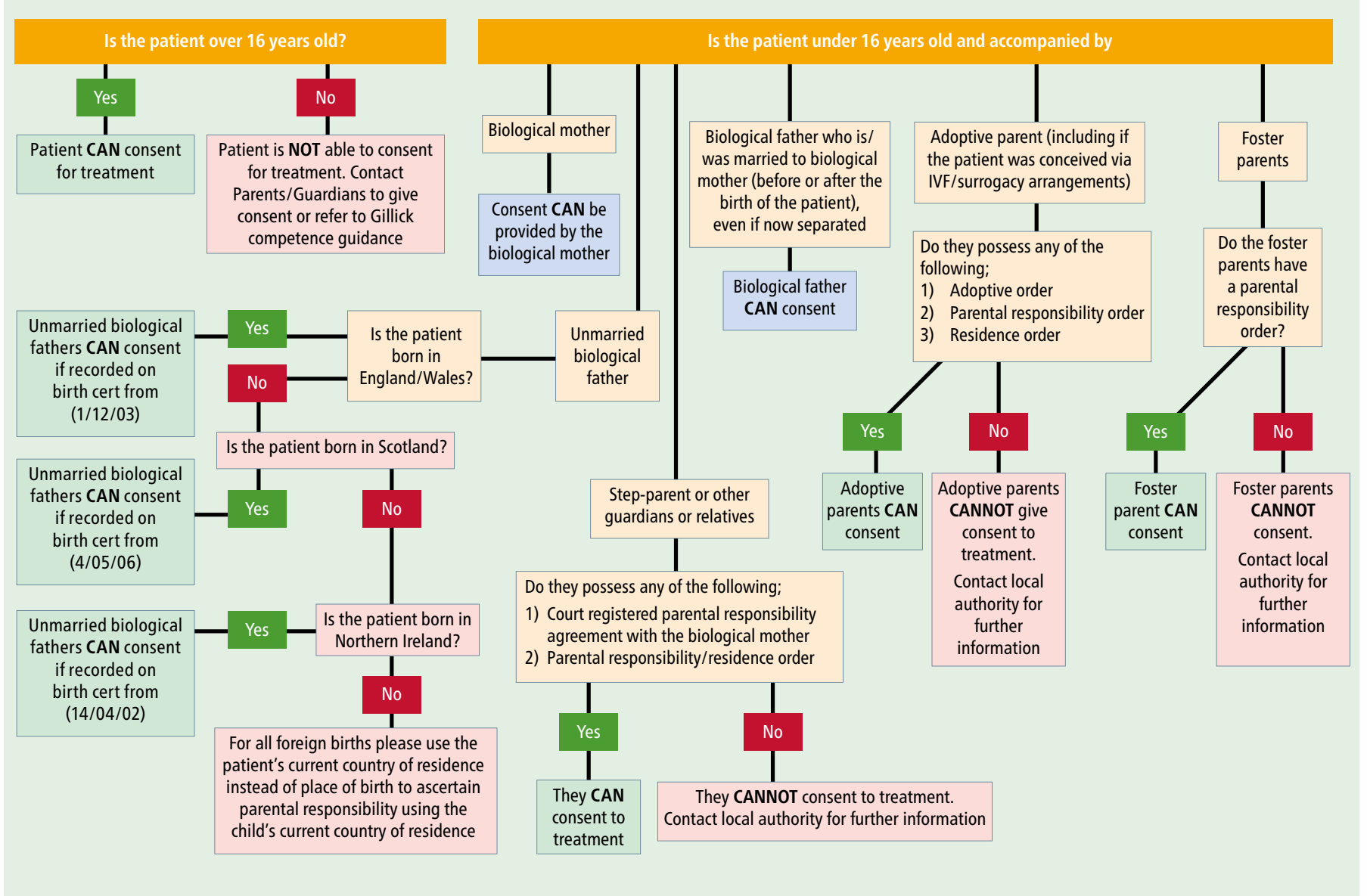


adult present with the patient has parental responsibility. ${ }^{18} \mathrm{~A}$ useful technique is to ask the child to confirm who is in attendance with them. There may be situations where individuals present may not have parental responsibility. It is important to ascertain whether the parents/ legal guardian are happy to have their presence during the consultation. The clinician must place emphasis that any discussion to be held is primarily aimed at the adult individual who has parental responsibility. It is important to ensure that the child/young person can be seen during the video consultation ${ }^{19}$ and the meeting should be conducted in a 'private space' for the patient; ${ }^{20}$ a communal space would be suitable, while a bedroom would not. Similar to a face-to-face consultation, a parent/ guardian should be present for the remote consultation. Video consultations should not be recorded unless explicit consent has been provided by the service user and this should be documented in the health records. ${ }^{18}$ The Royal College of Surgeons advises that the same principles of consent apply for virtual clinics as with face-to-face appointments; therefore, discussion of treatment options and consent can be undertaken. Prior to finishing, patients and/or their parent/carer should be informed of the next stage of their care and how they will be contacted. All discussions should be documented in the patient's health records in an accurate and contemporaneous manner to serve as reference for future consultations and for good record keeping. ${ }^{21}$ It would be beneficial to discuss and record who will sign and return the consent form and to arrange a further appointment if the patient or parent/guardian have further questions or would like more time to reflect on the treatment options.

\section{After the virtual consultation}

Following the virtual consultation, where necessary, a consent form can be sent to the patient via letter or electronically. Sufficient time should be provided for the patient and parents/guardian to reflect on the relevant information. ${ }^{22}$ The time required for each stage of the consent process may vary depending on the complexity of the procedure.

The right to access a child's health records following a dental appointment is governed by the principles of consent and parental responsibility. Although individuals with parental responsibility have the right to access the respective child's health records, in cases where the child has capacity to consent, consent for sharing information must first be sought from the child. Moreover, where a separated parent requests access to a child's record, if this in the child's best interests, the clinician could comply as above without seeking consent from the other parent. ${ }^{23}$

\section{Discussion}

As guidelines on consent and parental responsibility are ever evolving with the changing dynamics in patient autonomy and family structures, it is paramount that clinicians are kept up-to-date with current practice. A simple method of determining areas of knowledge deficit is through completion of self-assessment questionnaires and addressing areas of further development through continuing professional development. The results of our audit outline areas of knowledge deficit exist among clinicians in relation to consent and parental responsibility. Another audit conducted by Chate $(2008)^{24}$ also found that the gold standard was not met by orthodontic consultants in terms of knowledge of informed consent: a mean of $57 \%$ of the 11 questions were answered correctly. Consent and parental responsibility contain intrinsic nuances; therefore, respondents may not answer all questions correctly. As this topic is essential, the use of flowcharts on clinics (Fig. 1) and embedding an auto-populated parental responsibility form (Appendix 1) within the electronic records can greatly benefit patient care and clinician knowledge.

A form of neglect may be failure to ensure adequate supervision, for example through inadequate care-takers. ${ }^{25}$ Therefore, knowledge of who has parental responsibility for a patient is also important in flagging safeguarding concerns.

In the current digital age, where information is easily accessible, clinicians can use technology to their benefit in continuous learning and in utilising virtual consultations where appropriate. Although the principles of obtaining consent may not change significantly in the coming years, many clinicians are finding that there is a need to evolve the process of obtaining consent to keep pace with the digital age. There is an increasing desire by patients to have the option of telephone consultations and reported public satisfaction with telephone clinics is high. ${ }^{26}$ The COVID19 pandemic has also spurred a move towards virtual clinics. Advantages of these include increased flexibility, reduced costs, saved time and the observance of social distancing.

\section{Conclusion}

Clinicians should keep up to date with mercurial processes of obtaining consent and knowledge of parental responsibility. These principles relate to both face-to-face clinics and virtual clinics. Furthermore, clinicians undertaking virtual clinics should be adept in their knowledge of suitable encrypted apps to use and ways of ascertaining parental responsibility and consent.

\section{Ethics declaration}

The authors declare that there are no conflicts of interest.

\section{Acknowledgements}

The authors would like to thank Dr Andy Jones, Paediatric Specialist, for his work in developing the Parental Responsibility Form (Appendix 1).

\section{Author contributions}

All authors have contributed to the manuscript. Asma Keshtgar: helped write the manuscript, particularly sections on consent and teleclinics; was involved with designing and undertaking audit; and helped with revisions to the manuscript. Mohamed Hania: helped write the manuscript, particularly sections on parental responsibility and teleclincs; was involved with designing and undertaking audit; and helped with revisions to the manuscript. Mohammad O. Sharif: supervised and helped brainstorm manuscript content; was involved in audit design and the audit questionnaire; and was involved in reviewing the manuscript and providing revisions and feedback.

\section{References}

1. NHS. Consent to treatment. 2019. Available at https:// www.nhs.uk/conditions/consent-to-treatment/ (accessed September 2020).

2. General Dental Council. Standards for the Dental Team. 2013. Available at https://www.gdc-uk.org/informationstandards-guidance/standards-and-guidance/standardsfor-the-dental-team/ (accessed September 2020).

3. Swarb. Sidaway v Board of Governors of the Bethlem Royal Hospital and the Maudsley Hospital: HL 21 Feb 1985. 2021. Available at https://swarb.co.uk/sidawayv-board-of-governors-of-the-bethlem-royal-hospitaland-the-maudsley-hospital-hl-21-feb-1985/ (accessed September 2020).

4. Swarb. Bolam vs Friern Health Management Committee: QBD 1957. 2021. Available at https://swarb.co.uk/ bolam-v-friern-hospital-management-committeeqbd-1957/ (accessed January 2022).

5. Swarb. Montgomery v Lanarkshire Health Board: SCS $30 \mathrm{Jul}$ 2010. 2021. Available at https://swarb.co.uk/ montgomery-v-lanarkshire-health-board-scs-30jul-2010/ (accessed August 2020).

6. UK Government. Health and Social Care Act 2012 2012. Available at https://www.legislation.gov. uk/ukpga/2012/7/pdfs/ukpga_20120007_en.pdf (accessed August 2020).

7. Department of Health and Social Care. The NHS Constitution for England. 2021. Available at https:// www.gov.uk/government/publications/the-nhsconstitution-for-england/the-nhs-constitution-forengland (accessed September 2020). 
8. NHS. Shared decision making. 2019. Available at https://www.england.nhs.uk/shared-decision-making/ (accessed September 2020).

9. Stewart M, Brown J B, Donner A et al. The impact of patient-centered care on outcomes. J Fam Pract 2000 49: 796-804.

10. Wilson SR, Strub P, Buist A S et al. Shared treatment decision making improves adherence and outcomes in poorly controlled asthma. Am J Respir Crit Care Med 2010 181: 566-577.

11. Légaré F, Adekpedjou R, Stacey D et al. Interventions for increasing the use of shared decision making by healthcare professionals. Cochrane Database Syst Rev 2018: DOI: 10.1002/14651858.CD006732.pub4.

12. Dental Defence Union. Consent and young patients. 2018. Available at https://www.theddu.com/guidanceand-advice/guides/consent-and-young-patients (accessed October 2020)

13. Swarb. Gillick v West Norfolk and Wisbech Area Health Authority and Department of Health and Social Security: HL 17 Oct 1985. 2021. Available at https:// swarb.co.uk/gillick-v-west-norfolk-and-wisbech-areahealth-authority-and-department-of-health-andsocial-security-hl-17-oct-1985/ (accessed January 2022).

14. British Medical Association. Parental Responsibility and Consent. 2020. Available at https://www.bma.org.uk/ advice-and-support/ethics/seeking-consent/parentalresponsibility-and-consent (accessed September 2020).
15. Dental Protection. COVID-19 and remote consultations - how we can help. 202. Available at https://www. dentalprotection.org/uk/articles/covid-19-and-remoteconsultations-how-we-can-help (accessed October 2020).

16. General Medical Council. Remote consultations. 2020 Available at https://www.gmc-uk.org/ethical-guidance/ ethical-hub/remote-consultations (accessed September 2020).

17. NHS. Clinical guide for the management of remote consultations and remote working in secondary care during the coronavirus pandemic. 2020. Available at https://www.rcslt.org/wp-content/uploads/2021/10/ NHS-England-clinical-guide-for-the-managementof-remote-consultations-and-remote-working-insecondary-care-during-the-coronavirus-pandemic.pdf (accessed September 2020).

18. Healthcare Conferences UK. Information Governance, Consent and Legal Issues and Virtual Clinics. 2019. Available at https://www.healthcareconferencesuk. co.uk/assets/presentations-post-conference/ september-2019/setting-up-virtual-clinics-/mikeoconnell.pdf (accessed October 2020).

19. Royal College of Paediatrics and Child Health. Principles for conducting virtual consultations with children and young people. 2021. Available at https://www. rcpch.ac.uk/resources/principles-conducting-virtualconsultations-children-young-people\#arranging-avirtual-consultation (accessed February 2021).
20. General Medical Council. Remote consultations. 2021. Available at https://www.gmc-uk.org/ethical-guidance/ ethical-hub/covid-19-questions-and-answers\#Remoteconsultations (accessed February 2021).

21. General Dental Council. Standards for the Dental Team. 2013. Available at https://standards.gdc-uk.org/Assets/ pdf/Standards\%20for\%20the\%20Dental\%20Team.pdf (accessed November 2020).

22. Royal College of Surgeons of England. Tool 5: Consent to treatment, while COVID-19 is present in society. 2020. Available at https://www.rcseng.ac.uk/coronavirus/ recovery-of-surgical-services/tool-5/ (accessed September 2020).

23. Nunn J, Foster M, Master S, Greening S, British Society of Paediatric Dentistry. British Society of Paediatric Dentistry: a policy document on consent and the use of physical intervention in the dental care of children. 2008. Int J Paediatr Dent 2008; 18: 39-46.

24. Chate R A C. An audit of the level of knowledge and understanding of informed consent amongst consultant orthodontists in England, Wales and Northern Ireland. Br Dent J 2008; 205: 665-673.

25. British Dental Association. Child Protection and the Dental Team. 2009. Available at https:// bda.org/childprotection/Resources/Documents/ Childprotectionandthedentalteam_v1_4_Nov09.pdf (accessed November 2020)

26. Car J, Sheikh A. Telephone consultations. BMJ 2003; 326: 966-969.

\section{Parental Responsibility Form}

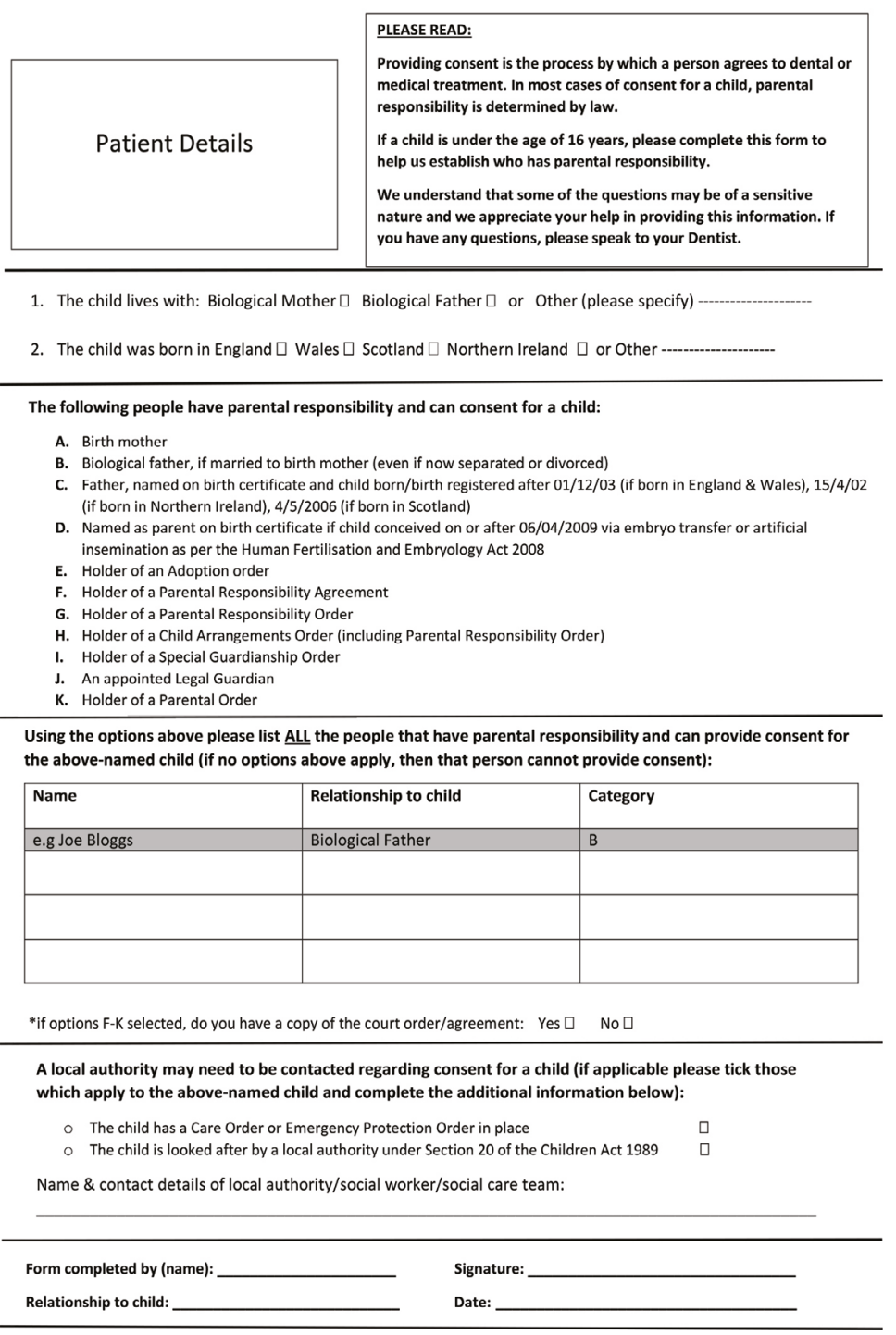

